\title{
Perancangan Pengalaman Pengguna dari Aplikasi Eksplorasi Kampus Institut Pertanian Bogor Menggunakan Metode Design Sprint
}

\section{User Experience Design of IPB University Campus Exploration Apps Using Design Sprint Method}

\author{
MASTUR FATULLAH ${ }^{1}$, AUZI ASFARIAN ${ }^{1 *}$
}

\begin{abstract}
Abstrak
Institut Pertanian Bogor (IPB) merupakan lembaga pendidikan yang memiliki kampus dengan luas wilayah 250 hektar di Dramaga, Bogor. Hal ini menyebabkan lokasi antara gedung berjauhan dan membuat pengguna sulit mendapatkan akses informasi tentang sarana dan prasarana. Tujuan dari penelitian ini adalah membangun rancangan aplikasi eksplorasi kampus IPB Dramaga berdasarkan kebutuhan pengguna yang memperhatikan aspek pengalaman pengguna dalam perancangannya. Penelitian ini menggunakan metode design sprint dengan dua kali iterasi. Penelitian ini menghasilkan prototipe medium-fidelity dari aplikasi tersebut. Pada iterasi pertama, prototipe telah diuji kepada tiga orang pengguna dengan tugas pengguna yang berkaitan dengan bis, mobil listrik, tempat penyewaan sepeda, gedung kuliah, tempat salat, kantin, dan parkir. Pada iterasi kedua, proses desain difokuskan pada pada transportasi bus dan diuji pada empat orang pengguna. Berdasarkan pengujian, seluruh pengguna menyatakan rancangan aplikasi sudah baik dan sesuai kebutuhan pengguna.
\end{abstract}

Kata Kunci: design sprint, eksplorasi, kampus, pengalaman pengguna.

\begin{abstract}
IPB University is a higher-education institution with over 250 hectares of campus area in Dramaga, Bogor. The vast size of the campus causes the location between buildings far apart and makes it difficult for users to navigate between facilities and infrastructures. In this study, we designed the user experience of campus exploration application to encourage the user to explore and familiarise themself with the campus and its facilities. We create the user experience using design sprint approach. This research produces a validated medium-fidelity prototype. We test the prototype to three to four students with tasks related to the discovery of buses, electric cars, bicycle residences, lecture halls, prayer rooms, canteens, and parking. In the second iteration, we improved the design of tasks related to the buses route and tracking and tested the design to four users. Based on the results of prototype testing data, all users declared the application design is good and according to their needs.
\end{abstract}

Keywords: campus, design sprint, exploration, user experience.

\section{PENDAHULUAN}

Kampus Institut Pertanian Bogor (IPB) Dramaga memiliki luas wilayah 250 hektar dengan jumlah mahasiswa mencapai 21176 orang (IPB 2018). Kendala yang dihadapi dari wilayah yang luas ini ialah sulitnya mendapatkan informasi mengenai sarana dan prasarana di Kampus IPB Dramaga, terutama untuk mahasiswa baru yang masih minim pengetahuan seputar sarana dan prasarana kampus. Pentingnya sarana seperti media belajar, transportasi dan prasarana seperti kantin, tempat berolahraga, tempat beribadah, dan tempat lainnya dalam suatu lembaga institusi pendidikan tertuang dalam Peraturan Pemerintah Republik Indonesia Nomor 19 Tahun 2005 Pasal 42. Sebagai lembaga institusi pendidikan, IPB memerlukan dukungan untuk kemudahan akses terhadap informasi sarana dan prasarana.

\footnotetext{
${ }^{1}$ Departemen Ilmu Komputer, FMIPA, Institut Pertanian Bogor.

*Penulis Korespondensi: Tel/Faks: 0251-8625584; Surel: asfarian@ apps.ipb.ac.id
} 
Salah satu cara untuk memberikan informasi mengenai akses tersebut adalah melalui suatu aplikasi eksplorasi kampus. Beberapa penelitian sebelumnya telah membuat aplikasi pengenalan kampus seperti yang dilakukan oleh Chao et al. (2014) dan Andri et al. (2018) yang memancing mahasiswa baru mengeksplorasi lingkungan kampusnya dengan menggunakan teknologi realitas tertambah. Untuk di Indonesia, penelitian Asfarian dan Ardiansyah (2012) serta Prasetia et al. (2018) membuat pengenalan kampus di Institut Pertanian Bogor (IPB) dan Universitas Siliwangi. Akan tetapi, penelitian-penelitian tersebut menunjukkan kekhasan dari informasi kampus yang akan disajikan kepada pengunjung atau mahasiswa. Walaupun penelitian Asfarian dan Ardiansyah (2012) dilakukan di IPB, yang dilakukan oleh aplikasi tersebut terbatas pada menampilkan nama dari bangunan-bangunan penting yang ada di IPB dengan menggunakan teknologi realitas tertambah. Selain itu, sejak tahun 2012, terdapat banyak perubahan sarana dan prasarana di IPB yang belum tercakup dalam aplikasi tersebut, seperti tempat penyewaan sepeda.

Pada penelitian ini, peneliti mengembangkan rancangan suatu aplikasi yang memungkinkan mahasiswa melakukan eksplorasi terhadap sarana dan prasarana yang dimiliki oleh Kampus IPB Darmaga. Aplikasi ini dirancang untuk mendukung kegiatan civitas akademika khususnya mahasiswa baru dalam mendapatkan kemudahan akses terhadap informasi sarana dan prasarana yang telah ada di kampus IPB Dramaga, sehingga tercapainya hasil yang diharapkan sesuai dengan rencana kegiatan, dan memberikan kenyaman dalam menjalankan aktivitas. Pengalaman pengguna dari aplikasi tersebut didesain dengan menggunakan prinsip Garrett (2011).

\section{METODE}

Penelitian ini menggunakan metode design sprint yang diperkenalkan oleh Knapp et al (2016). Metode ini memberikan suatu kerangka kerja bagi tim pengembang untuk menjawab suatu pertanyaan desain melalui lima tahap, yaitu understand, sketch, decide, prototype, dan validate (Asfarian et al. 2017). Penelitian ini dilakukan dengan dua kali iterasi, yaitu (a) mendesain aplikasi secara keseluruhan dan (b) memilih salah satu tugas pada aplikasi untuk didalami dengan lebih detail. Detail dari kelima tahap tersebut disajikan pada bagian berikut.

- Understand: Pada iterasi pertama, kuesioner dan wawancara digunakan untuk memahami kondisi target pengguna aplikasi, yaitu mahasiswa baru di Kampus IPB Darmaga. Kuesioner yang digunakan mengacu pada penelitian yang dilakukan Nadhirah (2014). Hasil dari kedua kegiatan tersebut kemudian dipetakan dalam bentuk diagram yang memperlihatkan proses pengguna dalam mencapai tujuannya.

- Sketch: Pada tahap ini, solusi untuk menjawab masalah yang digali pada tahap sebelumnya dicari dengan membangkitkan sebanyak mungkin ide dengan menggunakan teknik crazy eight. Teknik ini memaksa tim pengembangan untuk membangkitkan delapan buah ide berbeda dalam waktu sangat singkat untuk menyelesaikan masalah yang sama. Setelah dibangkitkan, beberapa ide yang potensial dipilih dan dilengkapi dengan sketsa yang lebih detail.

- Decide: Pada tahap ini, beberapa ide potensial dari tahap sebelumnya kembali dipilih untuk menghasilkan ide desain yang akan dikembangkan. Ide tersebut dilengkapi dengan skenario dan papan cerita yang sesuai dengan persona dari target pengguna. Papan cerita dibuat menjadi langkah demi langkah pengguna sebagai karakter utama dalam mencapai tujuannya.

- Prototype: Pada tahap ini, prototipe aplikasi dirancang berdasarkan skenario dan papan cerita yang telah dibuat. Prototipe yang dibuat mencerminkan perilaku perangkat lunak dan menggambarkan interaksi yang dapat dilakukan oleh pengguna. Prototipe ini harus dapat merepresentasikan look, feel, dan behavior serta interaksi yang dilakukan berdasarkan skenario yang dibuat (Nadhirah 2014; Galitz 2002). Prototipe dibuat menggunakan lisensi 
edukasi Axure RP Pro 8.0 dengan memperhatikan perancangan elemen-elemen visual dan standar Google Material Design Guidelines.

- Validate: Prototipe aplikasi divalidasi melalui tahapan wawancara terstruktur untuk menggali informasi dan menguji kesesuaian prototipe oleh mahasiswa IPB angkatan 54 (tahun masuk 2017) sebagai pengguna. Pada iterasi pertama, pengujian prototipe dilakukan kepada tiga orang pengguna dan kegiatan yang dilakukan pada saat wawancara dapat dilihat pada Tabel 2. Pada iterasi kedua, pengujian prototipe dilakukan kepada empat orang pengguna dan kegiatan yang dilakukan pada saat wawancara dapat dilihat pada Tabel 3 . Tahapan wawancara dibagi menjadi lima tahap, yaitu: friendly welcome, context question, introduce the prototype, tasks, dan quick debrief (Knapp et al. 2016).

\section{HASIL DAN PEMBAHASAN \\ Understand}

Pemetaan masalah dilakukan dengan cara survei kebutuhan pengguna kepada tiga puluh empat responden mahasiswa IPB angkatan 54 (tahun masuk 2017) secara daring. Pertanyaan yang diajukan terdiri dari tiga bagian yaitu sarana dan prasarana, penggunaan telepon seluler, dan kebutuhan serta respon terhadap aplikasi eksplorasi kampus IPB yang akan diracang. Data hasil survei sebanyak 56\% menyatakan puas mengenai sarana dan prasarana yang tersedia di kampus IPB Dramaga. Akan tetapi, sebanyak 65\% belum menyatakan puas terhadap kemudahan akses informasi sarana dan prasarana yang tersedia. Seluruh responden memiliki telepon seluler, sebanyak $84 \%$ selalu dan sering terhubung dengan koneksi internet. Sebanyak $90 \%$ responden menunjukan minat yang tinggi untuk mengunduh dan menggunakan aplikasi eksplorasi kampus IPB. Skala dari 1-5, sebanyak $25 \%$ orang responden memberi angka 4, dan $65 \%$ responden memberi angka 5 terhadap manfaat informasi yang ditawarkan. Berdasarkan data kuesioner dan wawancara tersebut, dibuatlah persona (Gambar 1) dan peta pengalaman (Gambar 2) untuk menggambarkan pengalaman pengguna saat mengeksplorasi Kampus IPB Darmaga.

Dari studi literatur, diperoleh pula bahwa perilaku pengguna internet Indonesia beralih ke mobile-first akibat semakin banyaknya masyarakat yang memilik ponsel pintar (Puspitasari dan Ishii 2016). Berdasarkan Statista (2020), pengguna ponsel pintar di Indonesia pada tahun 2020 mencapai 30\% dari penduduk Indonesia. Angka ini lebih besar di kalangan mahasiswa. Sebagai konsekuensinya, semakin banyak layanan yang lebih sering diakses melalui media ponsel pintar.

Tabel 1 Pertanyaan kuesioner

\begin{tabular}{cl}
\hline No & \\
\hline 1 & Biodata \\
2 & Bagaimana sarana dan prasarana yang ada di kampus IPB Dramaga? \\
3 & Bagaimana akses terhadap informasi sarana dan prasarana yang ada di kampus IPB Dramaga? \\
4 & Jika diberikan skala 1-10, angka berapa yang Anda berikan sebagai kepuasan terhadap sarana dan prasarana saat \\
& berada di kampus IPB Dramaga \\
5 & Ceritakan hal buruk apa yang pernah anda alami terhadap sarana dan prasarana yang ada di kampus IPB Dramaga \\
6 & Apakah Anda memiliki telepon seluler? \\
7 & Apakah telepon seluler Anda terhubung dengan koneksi internet? \\
8 & Sistem operasi perangkat mobile Anda? \\
9 & Aplikasi yang paling sering Anda gunakan pada perangkat mobile? \\
10 & Jika ada sebuah sistem yang dapat memberitahu sarana-prasarana yang ada di kampus IPB Dramaga melalui \\
& telepon seluler, apakah sistem tersebut akan bermanfaat? \\
11 & Jika ada sebuah sistem berbasis mobile yang dapat keberadaan sarana seperti bus kampus secara real-time melalui \\
& telepon seluler. Apakah berniat mengunduh dan menggunakannya? \\
12 & Apakah perlu ada fungsi untuk menambahkan tootlip (pesan, kesan, saran, dsb) untuk setiap sarana-prasarana yang \\
& ada di Kampus IPB Dramaga?
\end{tabular}


Tabel 2 Pertanyaan wawancara pada iterasi pertama

\begin{tabular}{|c|c|}
\hline Tahapan & Kegiatan dan pertanyaan \\
\hline Friendly Welcome & - Memulai pembicaraan dengan santai, berkenalan, dan basa basi. \\
\hline Context Question & $\begin{array}{l}\text { - Kegiatan apa saja yang anda lakukan selama berada di kampus? } \\
\text { - Selama anda berada di kampus, sarana dan prasarana apa saja yang anda ketahui dan yang } \\
\text { anda gunakan? } \\
\text { - Bagaimana cara mendapatkan informasi terhadap sarana dan prasarana? } \\
\text { - Informasi apa saja yang diperlukan untuk sarana dan prasarana yang ada di kampus? } \\
\text { - Selama berada di kampus untuk bepergian dari satu tempat ke tempat lain menggunakan } \\
\text { apa? Transportasi kampus apa yang digunakan? } \\
\text { - Apa kendala saat menggunakan sarana dan prasarana di kampus IPB Dramaga? } \\
\text { - Apa perangkat elektronik yang anda gunakan? }\end{array}$ \\
\hline Introduce the Prototype & - - \\
\hline Task & $\begin{array}{l}\text { - Aplikasi mulai ditunjukan kepada mahasiswa } \\
\text { - Jelaskan apa itu aplikasi Eksplorasi Kampus IPB Dramaga } \\
\text { - Memberikan maksud dan tujuan bahwa kita perlu bantuan dari saurdara/i agar aplikasi } \\
\text { dapat berjalan dengan baik. }\end{array}$ \\
\hline Debrief & $\begin{array}{l}\text { - Menanyakan pendapat tentang aplikasi eskplorasi kampus? } \\
\text { - Menanyakan saran untuk kedepannya. (tambahan untuk aplikasi dsb) } \\
\text { - Apakah mau memakai aplikasi ini kedepannya? }\end{array}$ \\
\hline
\end{tabular}

Tabel 3 Pertanyaan wawancara pada iterasi pertama

\begin{tabular}{|c|c|}
\hline Tahapan & Kegiatan dan pertanyaan \\
\hline Friendly Welcome & - Memulai pembicaraan dengan santai, berkenalan, dan basa basi. \\
\hline Context Question & $\begin{array}{l}\text { - Kegiatan apa saja yang anda lakukan selama berada di kampus? } \\
\text { - Sudah berapa lama berada di kampus IPB? } \\
\text { - Selama anda berada di kampus pernahkah menggunakan transportasi bus? Apa kendala } \\
\text { - yang dihadapi? } \\
\text { - Bagaimana cara mendapatkan informasi terhadap sarana transportasi bus? } \\
\text { - Perangkat elektronik apa yang sering digunakan? }\end{array}$ \\
\hline Task & $\begin{array}{l}\text { - Aplikasi mulai ditunjukan kepada mahasiswa } \\
\text { - Jelaskan apa itu aplikasi Eksplorasi Kampus IPB Darmaga } \\
\text { - Memberikan maksud dan tujuan bahwa kita perlu bantuan dari pengguna agar aplikasi } \\
\text { dapat berjalan dengan baik. }\end{array}$ \\
\hline Debrief & $\begin{array}{l}\text { - Menanyakan pendapat tentang aplikasi eksplorasi kampus? } \\
\text { - Menanyakan saran untuk kedepannya. (tambahan untuk aplikasi dsb) } \\
\text { - Apakah mau memakai aplikasi ini kedepannya? }\end{array}$ \\
\hline
\end{tabular}

\section{Sketch}

Crazy 8 dan menghasilkan beberapa ide berupa menu utama, pencarian rute bis, informasi rute pencarian, daftar mobil listrik, daftar tempat, informasi tempat, search keyword, dan chatbox (Gambar 3). Ide-ide utama dalam perancangan aplikasi untuk membantu pengguna mendapatkan akses terhadap informasi sarana prasrana adalah transportasi, lokasi, dan wisata. Ide transportasi dipilih karena memiliki peranan penting membantu pengguna di kampus IPB Dramaga untuk sampai ke tempat tujuan sehingga lebih efisien. Tempat seperti gedung kuliah, kantin, tempat salat, dan sebagainya harus memiliki lokasi dan informasi yang jelas bagi pengguna. IPB yang memiliki konsep agroeduturism menjadikan destinasi wisata untuk memperkenalkan tempat-tempat menarik di wilayah kampus IPB Dramaga. Tiga ide utama tersebut kemudian dikategorikan menjadi delapan fitur utama, yaitu bis, mobil listrik, gedung kuliah, tempat salat, tempat penyewaan sepeda, kantin, area parkir, dan tempat wisata. Masingmasing memiliki konten untuk perancangan pada aplikasi eksplorasi kampus IPB Dramaga.

Kemudian, sketsa dibuat dengan tujuan untuk membuktikan penerapan user experience yang tepat untuk aplikasi eksplorasi kampus IPB Dramaga. Hasil sketsa tersebut dapat dilihat pada Gambar 4. Gambar tersebut menunjukkan proses penggambaran sketsa untuk transportasi dan tempat yang ada di wilayah kampus IPB Dramaga. Sketsa transportasi bis memperlihatkan kotak pencarian rute halte dengan memilih halte asal dan tujuan. Setelah memilih selanjutnya muncul layer rute halte yang dilalui, informasi bus yang tersedia, dan waktu sampai tujuan setiap halte. Sketsa tempat, pengguna dapat memilih daftar tempat yang tersedia, daftar yang 
ditampilkan menampilkan informasi nama tempat, jarak tempat dengan posisi pengguna, dan status tempat, selain itu ketika pengguna memilih tempat maka akan menampilkan layer informasi detail mengenai kontak penanggung jawab, fasilitas tempat, maps, status tempat, dan ikon lokasi ke tempat tujuan.

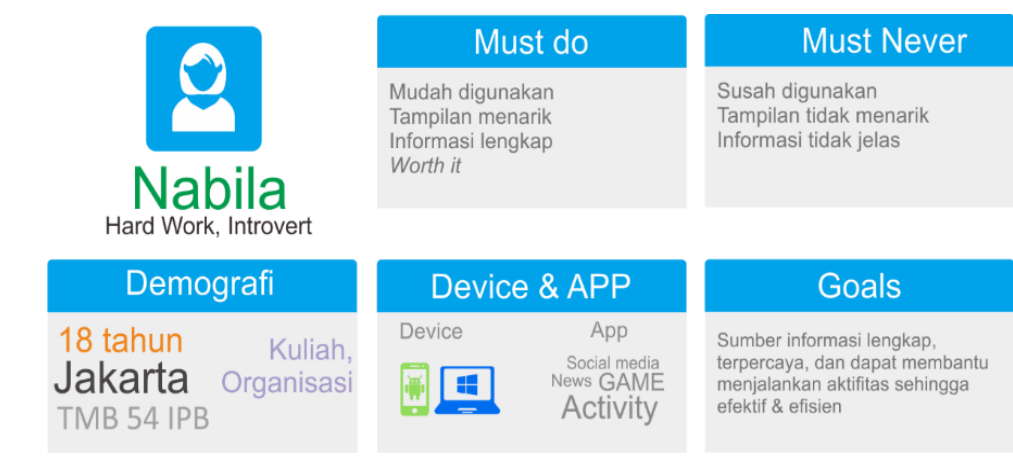

Gambar 1 Persona dari target pengguna aplikasi eksplorasi kampus.

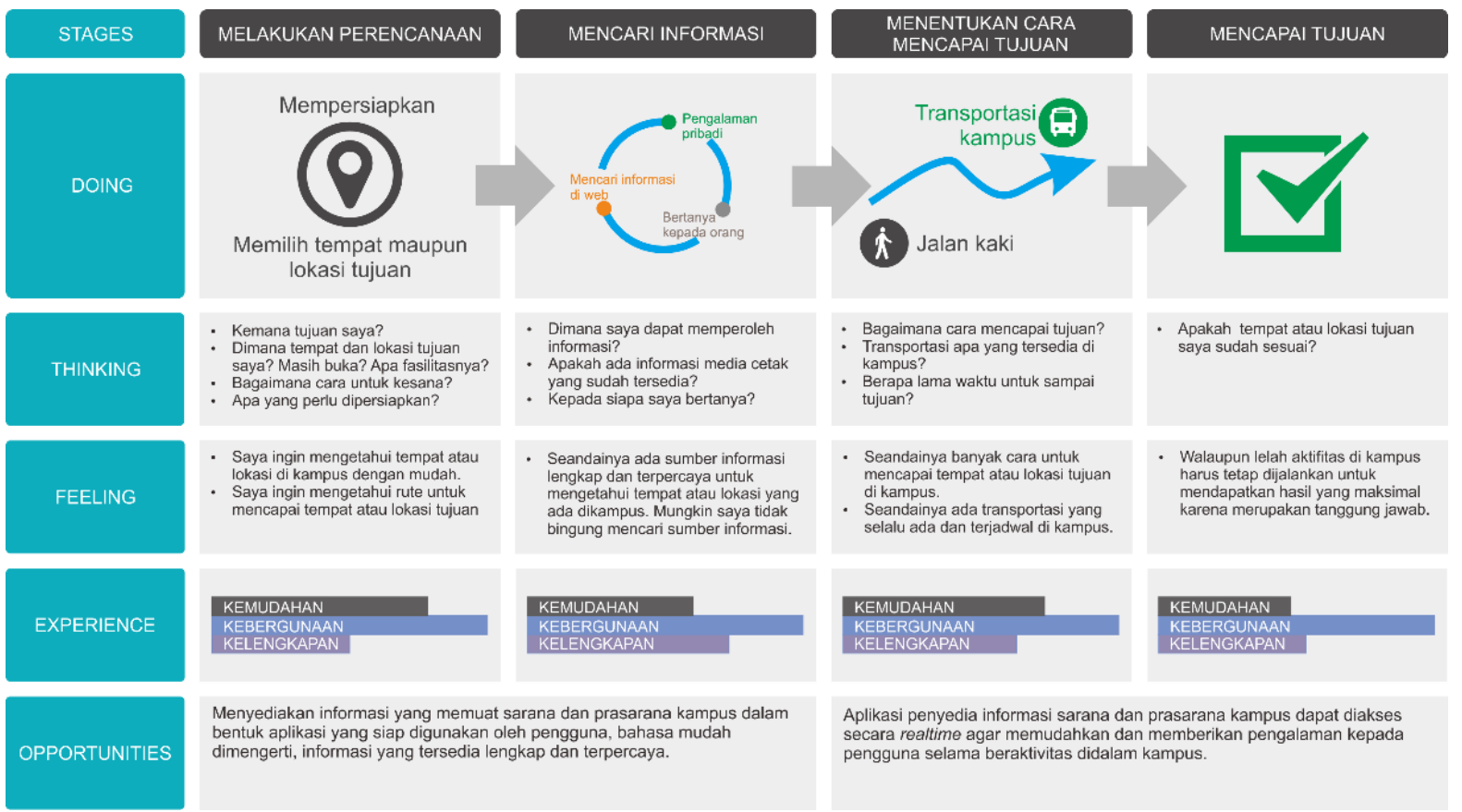

Gambar 2 Peta pengalaman dari pengguna.
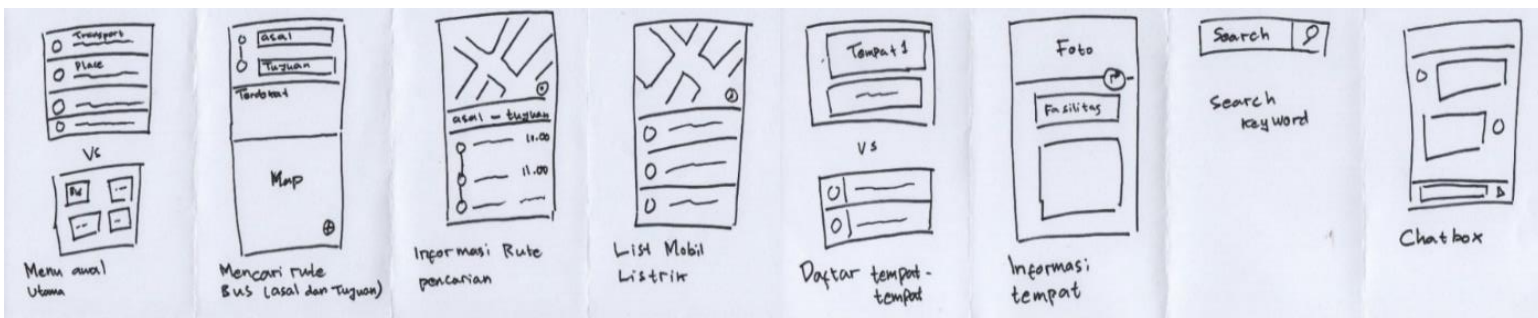

Gambar 3 Hasil kegiatan crazy eight.

\section{Decide}

Pada tahap ini dibuat papan cerita dan skenario. Detail skenario dapat dilihat pada Gambar 5. Skenario dimulai ketika pengguna sedang berada di kampus IPB Dramaga dan menerima pesan singkat berupa tautan aplikasi eksplorasi kampus. Pengguna membuka tautan, dan menginstal aplikasi. Pengguna membuka aplikasi dan masuk ke menu utama. Kemudian, pengguna memilih fitur tempat, dan aplikasi menampilkan daftar tempat yang tersedia. Daftar tempat memiliki foto, nama tempat, status, serta jarak tempat, dan status tempat. Selanjutnya, 
pengguna memilih dan menyentuh salah satu tempat, aplikasi menampilkan informasi umum, kontak, alamat, fasilitas, dan arahan menuju tempat tersebut melalui Google maps.

Setelah itu, pengguna mencari rute dari moda transportasi bis. Ia masuk ke halaman fitur transportasi bis dan mengisi halte asal dan tujuan dari transportasi bis. Pada halaman hasil pencarian rute, terdapat peta yang menampilkan ikon halte asal, halte tujuan, halte-halte yang dilewati, posisi bus secara real-time, dan posisi lokasi pengguna saat itu. Pada halaman yang sama, terdapat juga informasi dan petunjuk rute yang dilewati. Ketika pengguna memilih moda transportasi mobil listrik (moli), aplikasi akan menampilkan daftar moli yang tersedia beserta jarak dari posisi moli ke pengguna. Jika pengguna menyentuh satu daftar moli, aplikasi akan menampilkan rute dari posisi pengguna ke posisi moli.

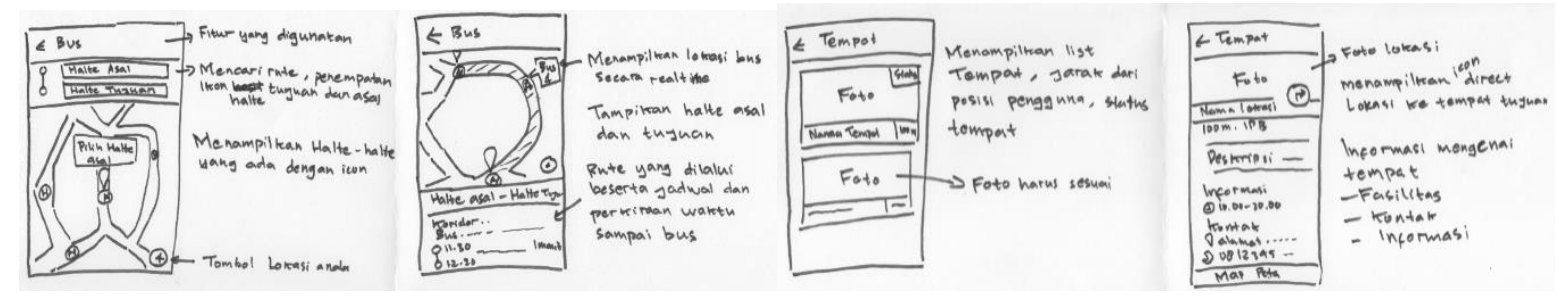

Gambar 4 Sketsa iterasi pertama.

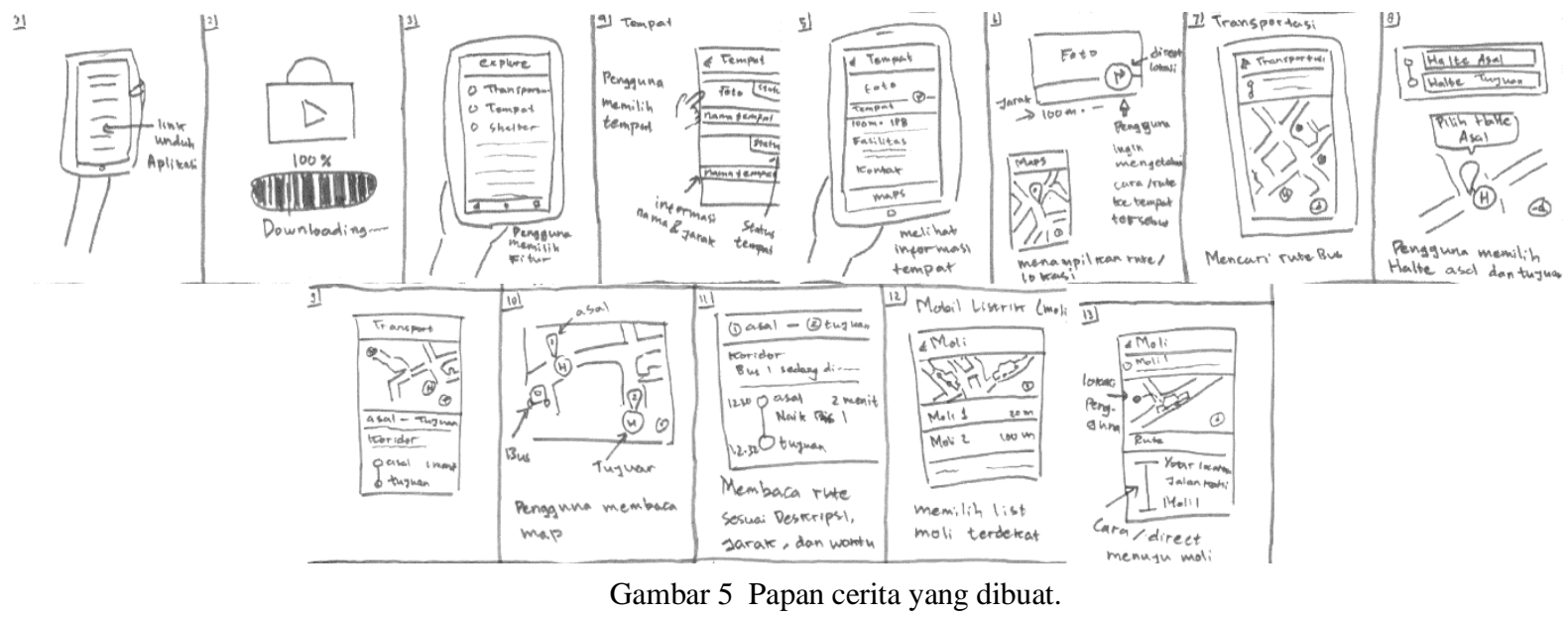

\section{Prototype}

Pada tahapan prototipe, warna utama yang dipilih untuk aplikasi adalah hijau (kode hexa: \#34a853) dan latar berwarna putih (kode hexa: \#ffffff). Pada proses perancangangan, prototipe terdiri atas sepuluh halaman utama yaitu menu, bus, hasil pencarian rute bis, daftar moli, hasil lokasi moli, dan tempat yaitu gedung kuliah, tempat peminjaman sepeda, tempat salat, kantin, dan parkir. Halaman untuk fitur yang berkaitan dengan transportasi dapat dilihat pada Gambar 6, sedangkan untuk tempat dapat dilihat pada Gambar 7.

\section{Validate}

Pengujian dilakukan dengan cara merekam suara ketika wawancara dan aktivitas pengguna saat menggunakan prototipe. Pengujian dilakukan kepada tiga orang responden mahasiswa angkatan 54 (tahun masuk 2017) bergantian secara tatap muka di kampus IPB Dramaga. Waktu pengujian setiap tatap muka berlangsung sekitar 15-45 menit. Kegiatan pada saat pengujian kepada pengguna dapat dilihat pada Gambar 8.

Berdasarkan hasil wawancara tahap task dan quick debrief terlihat bahwa ada beberapa hal yang belum diakomodasi oleh prototipe aplikasi eksplorasi kampus IPB Dramaga. Informasi mengenai detail dari setiap ruangan yang belum tersedia serta informasi rute dan jadwal transportasi kampus yang masih belum tersedia pada prototipe aplikasi. Informasi jumlah sepeda yang tersedia tidak terbaca oleh pengguna ketika menggunakan prototipe aplikasi. Namun demikian, hasil dari keselurahan wawancara dapat ditarik kesimpulan bahwa 
rancangan aplikasi yang diinginkan oleh pengguna sudah sesuai dengan ekspetasi. Informasi umum mengenai sarana transportasi dan prasarana tempat yang ditampilkan pada rancangan aplikasi dilengkapi petunjuk sehingga dapat dan mudah digunakan untuk menunjang kegiatan sehari-hari pengguna selama berada kampus IPB Dramaga. Selain itu, pengguna menginginkan informasi real-time dari rancangan sistem informasi yang disuguhkan oleh aplikasi.

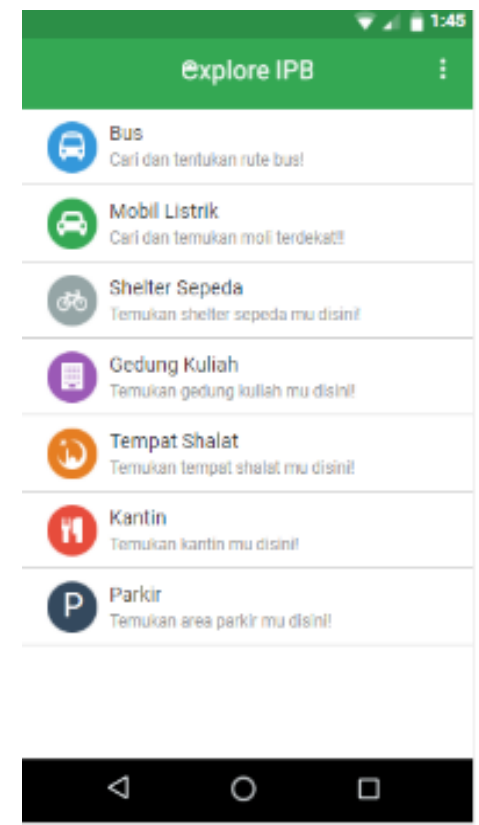

(a) Menu utama.

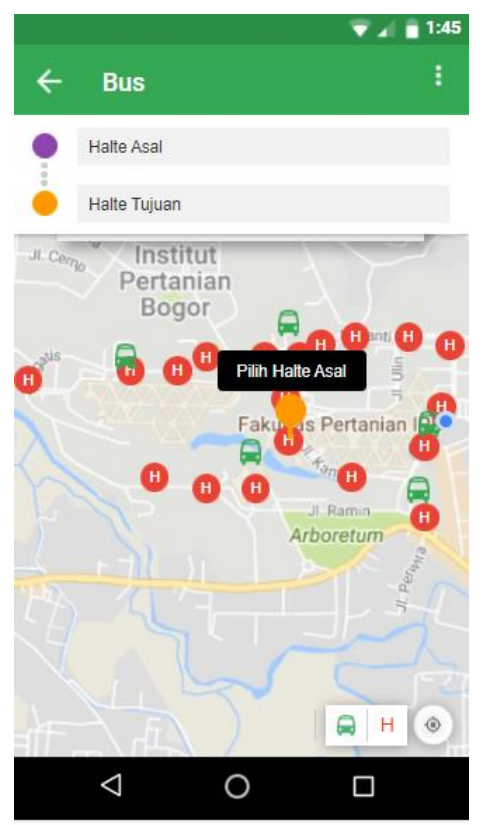

(b) Fitur peta bus.

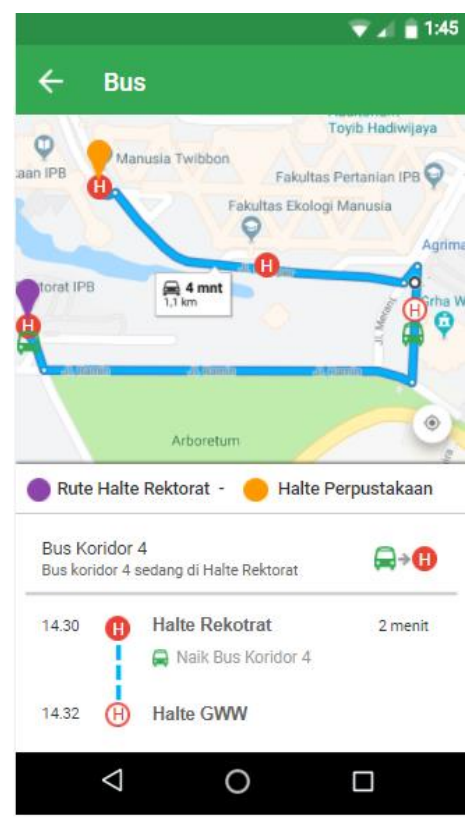

(c) Hasil pencarian rute.

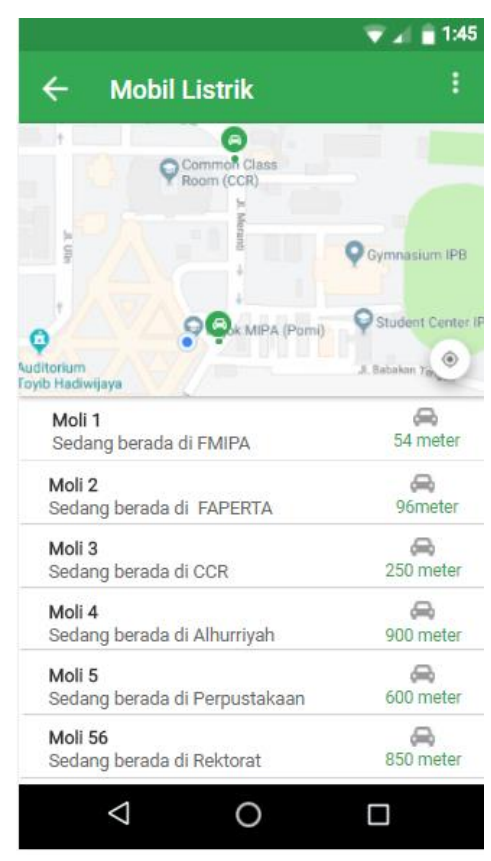

(d) Mobil listrik.

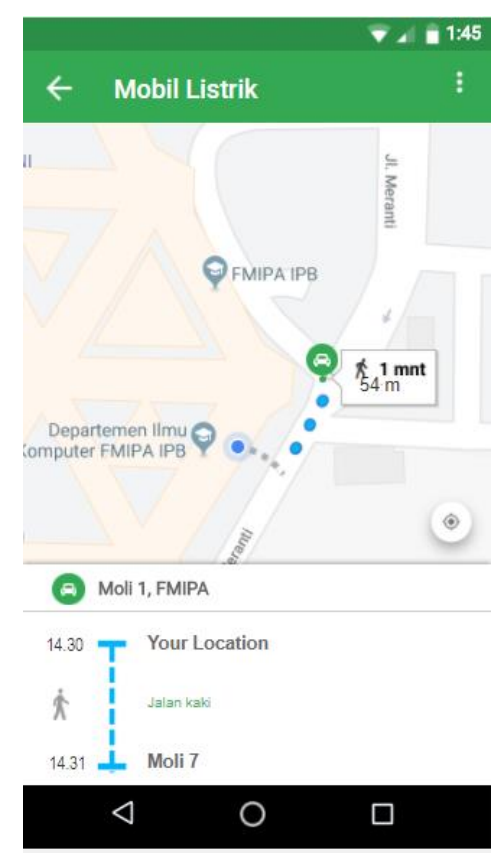

(e) Rute mobil listrik.

Gambar 6 Beberapa cuplikan dari prototipe aplikasi yang berkaitan dengan transportasi. 


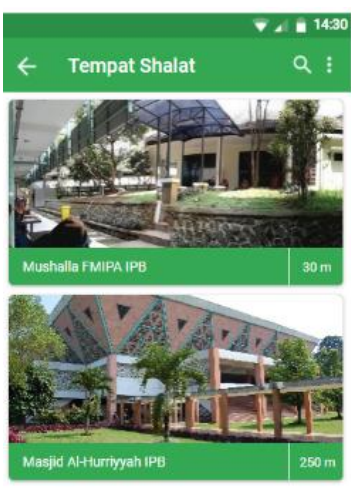

$\triangleleft$
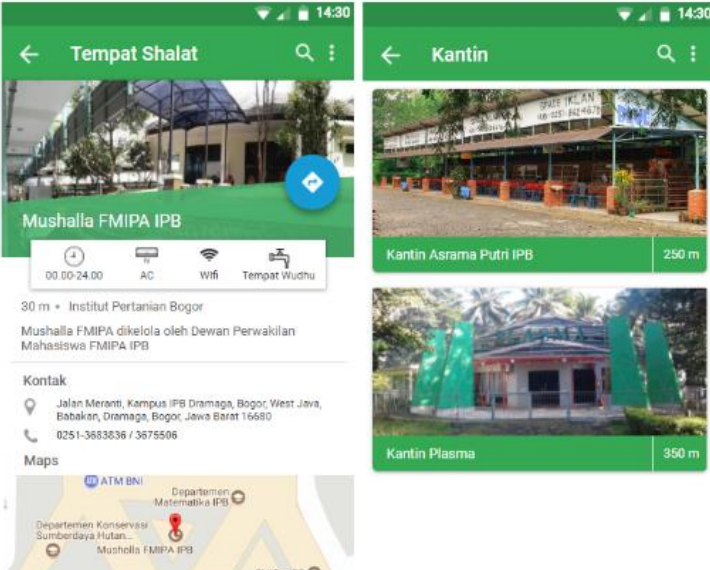

Kantin Plasm
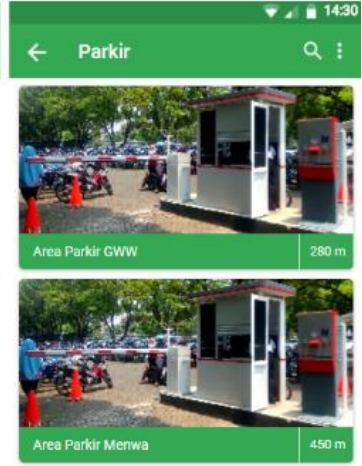

Area Parkiri Menwa

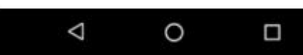

Gambar 7 Beberapa cuplikan dari prototipe aplikasi yang berkaitan dengan lokasi.
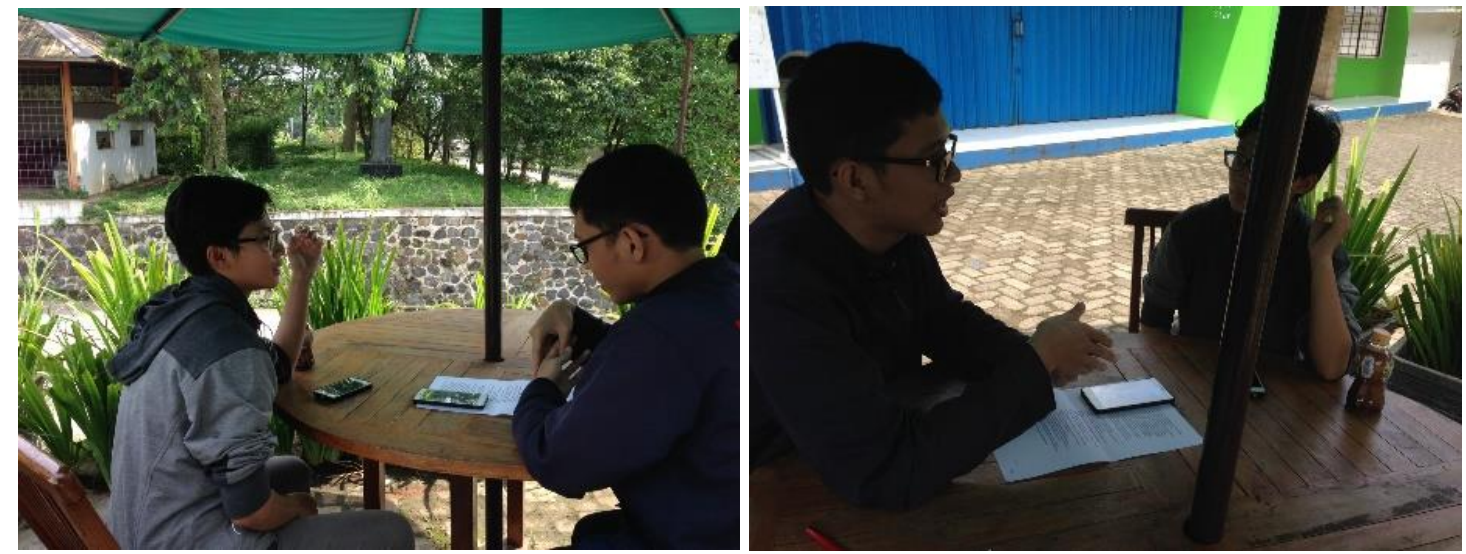

Gambar 8 Suasana pengujian kepada pengguna.

\section{Perbaikan pada Iterasi Kedua}

Berdasarkan hasil tahap validate di iterasi pertama, perancangan pada iterasi kedua berfokus pada pengembangan transportasi bis. Moda transportasi bis dipilih karena memungkinkan untuk direalisasikan, bis lebih sering beroperasi, dan bisa menjangkau luas wilayah kampus IPB Dramaga. Selain itu, fokus transportasi bis dipilih untuk mendukung terlaksananya kebijakan menuju green campus tahun 2020 di kampus IPB Dramaga.

Pada iterasi kedua terdapat perubahan dan penambahan konten rancangan transportasi dari iterasi sebelumnya. Perubahan dan penambahan fitur dilakukan berdasarkan wawancara dengan responden. Berdasarkan hasil wawancara tersebut dapat ditarik kesimpulan bahwa responden masih merasa kebingungan menggunakan fitur bis. Beberapa masalah tersebut seperti pada saat pencarian rute ketika memilih halte asal dan tujuan, waktu tiba bis, kurangnya informasi yang jelas mengenai koridor, dan juga informasi umum bis. Proses berikutnya kembali mengikuti tahap pada design sprint dan menghasilkan beberapa keluaran seperti papan cerita (Gambar 9) dan perubahan antarmuka (Gambar 10).

Pengujian pada iterasi kedua dilakukan dengan cara merekam suara ketika wawancara dan aktivitas pengguna saat menggunakan prototipe. Pengujian masih dilakukan secara bergantian kepada 4 orang responden mahasiswa angkatan 54 (tahun masuk 2017) di kampus IPB Dramaga. Solusi untuk menjawab masalah-masalah yang terdapat pada hasil validate iterasi pertama sudah ditambahkan pada rancangan prototipe iterasi kedua seperti informasi rute dan jadwal transportasi bis. Rancangan aplikasi yang dibuat telah memuat informasi pencarian rute untuk menghemat pengguna dalam pemilihan rute, jadwal kedatangan bis mengurai waktu tunggu pengguna selama berada di halte, informasi koridor dan informasi umum menjadikan pengguna tidak ragu untuk menggunakan transportasi bis selama beraktifitas di kampus IPB Dramaga. Berdasarkan, hasil wawancara tahap task dan quick debrief iterasi kedua diperoleh 
kesimpulan bahwa seluruh pengguna menyatakan rancangan aplikasi eksplorasi kampus IPB Dramaga sudah baik dan sesuai dengan kebutuhan pengguna. Sedangkan untuk pengembangan berikutnya harus ditunjang oleh fasilitas pendukung dilapangan agar rancangan dapat direalisasikan menjadi sebuah aplikasi yang dapat dirasakan manfaatnya oleh pengguna.

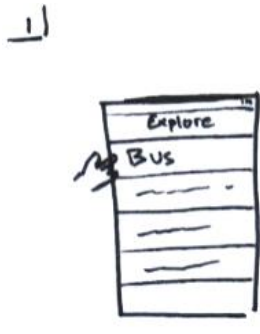

Pengguna memilih Fiwar Bus

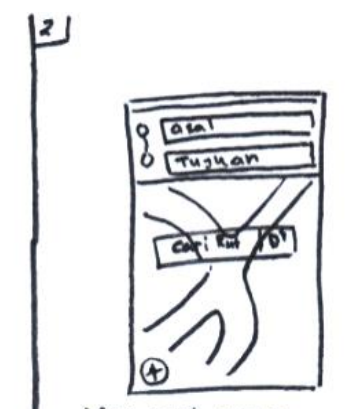

Mencari rute berdasarkan asal

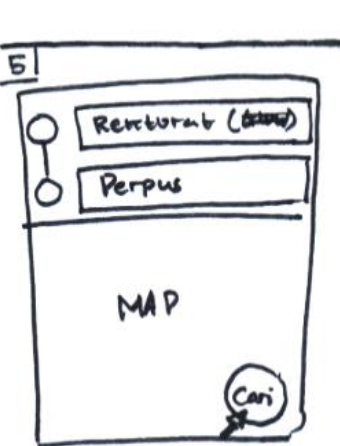

Klik button cari

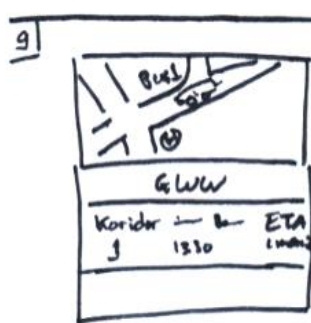

Pengguna melihat

Jadwal redatanyan

ins setiap halte Rute

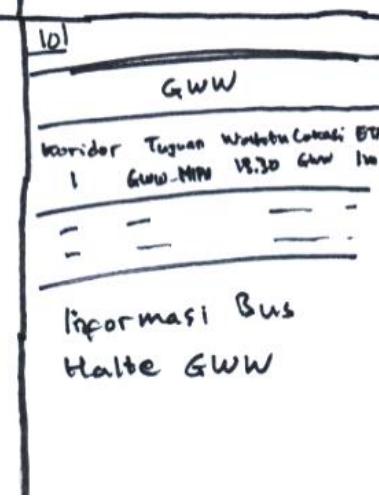

3) 4

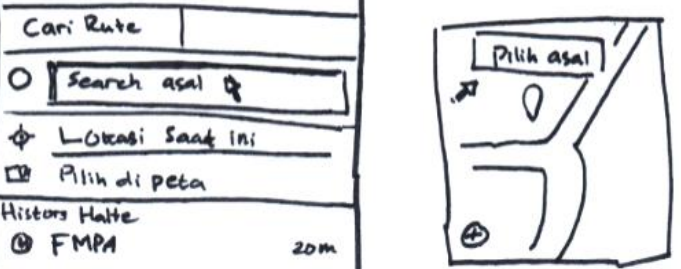

Pick lukasi di pela

Memilih asal/tuguan

(8)

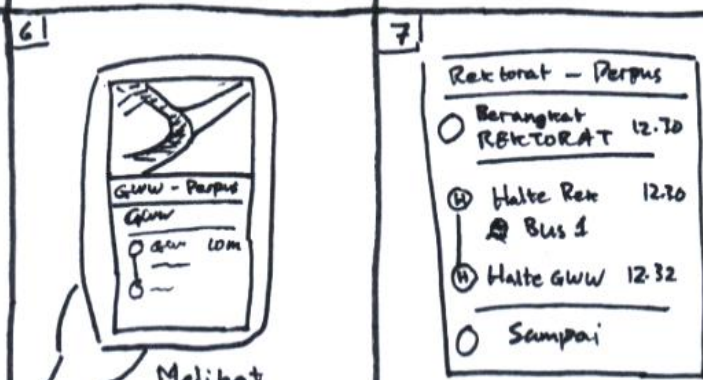

Baca Informasi langrea demi langtarh

(II)

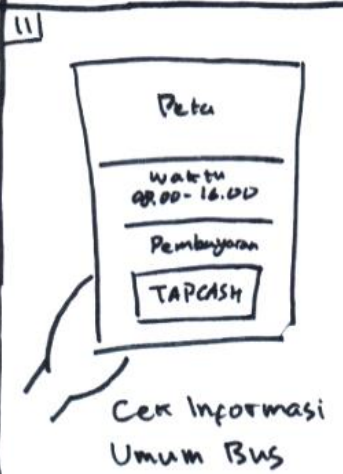

121

unture melihat Jalur halte boridor

Gambar 9 Papan cerita dari perbaikan di iterasi kedua.

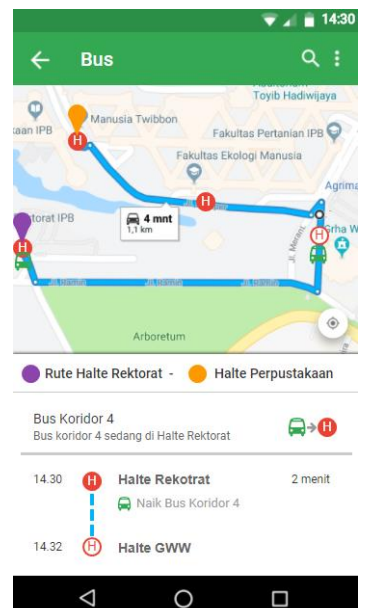

(a) perubahan pada informasi rute.
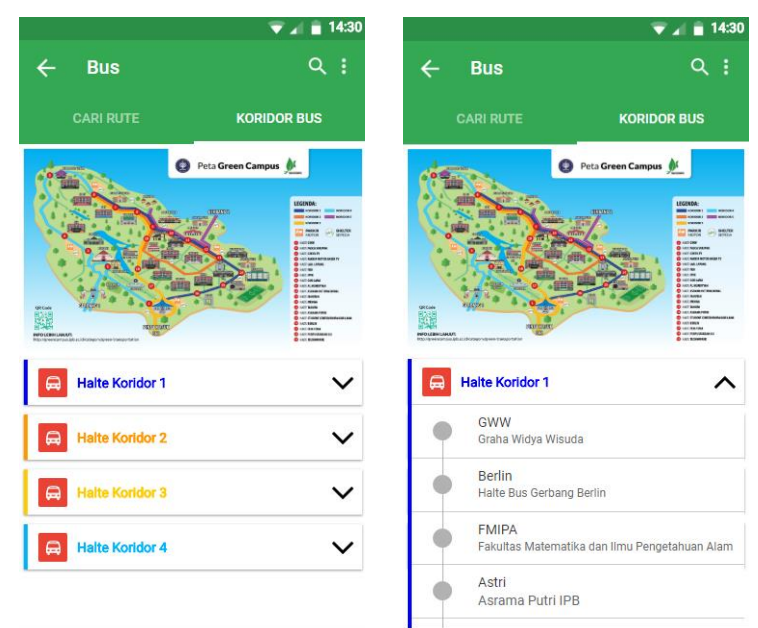

(a) perubahan pada informasi koridor bus.

Gambar 10 Contoh perubahan halaman pada iterasi kedua. 


\section{SIMPULAN}

Prototipe aplikasi eksplorasi kampus IPB Dramaga dibuat pada tahap medium-fidelity dengan memperhatikan aspek pengalaman pengguna berdasarkan kebutuhan pengguna yang melibatkan tiga puluh empat orang responden untuk tahapan awal perancangan. Prototipe dikembangan melalui proses dua tahap iterasi. Prototipe iterasi pertama memiliki tujuh fitur utama yaitu bis, mobil listrik, tempat peminjaman sepeda, gedung kuliah, tempat salat, kantin, dan parkir telah diuji kepada tiga orang pengguna. Prototipe iterasi kedua dikembangkan dengan memilih fokus transportasi bis yang menampilkan lima konten informasi yaitu pencarian rute, hasil pencarian rute, koridor, informasi umum, dan jadwal telah diuji kepada empat orang pengguna.

Hasil pengujian kepada pengguna pada iterasi pertama diperoleh masalah yaitu kurangnya informasi detail ruangan, informasi jumlah sepeda, rute bis, posisi, dan jadwal kedatangan transportasi bis. Masalah yang ditemukan pada iterasi pertama dibuat menjadi sebuah solusi yang ditambahkan kedalam rancagan prototipe iterasi kedua. Hasil pengujian iterasi kedua setelah dilakukan penambahan dan perubahan fitur prototipe dari tahapan iterasi pertama, dapat diperoleh kesimpulan bahwa seluruh pengguna menyatakan rancangan prototipe aplikasi eksplorasi kampus IPB Dramaga sudah baik dan sesuai dengan kebutuhan pengguna mahasiswa angkatan 54.

\section{DAFTAR PUSTAKA}

Andri AC, Alkawaz MH, Sallow AB. 2018. Adoption of Mobile Augmented Reality as a Campus Tour Application. Int. J. Eng. Technol.

Asfarian A, Ardiansyah F. 2012. Rekayasa Augmented Reality Mobile Campus Tour Institut Pertanian Bogor. Jurnal Ilmu Komputer dan Agri-Informatika, 1(1):1-6.

Asfarian A, Solahudin F, Wahjuni S, Nurhadryani Y, Ardiansyah F, Ramadhan DA. 2017. Evaluasi usabilitas dan analisis pengalaman pengguna untuk peningkatan kualitas sistem manajemen pengetahuan komoditas kedelai untuk penyuluh. Di dalam SESINDO 9. Bali, 2017 Nov 24; hlm 25-34.

Chao JT, Pan L, Parker KR. 2014. Campus event app-New exploration for mobile augmented reality. Issues in Informing Science and Information Technology, 11(1):001-11.

Galitz OW. 2002. The Essential Guide to User Interface Design. Ed ke-2. US: John Wiley \& Sons.

Garrett JJ. 2011. The Elements of User Experience: User-Centered Design for the Web and Beyond. Ed ke-2. Berkeley (US): New Riders.

[IPB] Institut Pertanian Bogor. 2018. Tentang IPB [Internet]. [diakses 2018 Mei 23]. Tersedia pada: ipb.ac.id/page/about

Knapp J, Zerstsky J, Kowitz B. 2016. Sprint: How to Solve Big Problems and Test New Ideas in Just Five Days. New York (US): Simon \& Schuster

Nadhirah ASD. 2014. Perancangan mobile user experience aplikasi visit puncak untuk perkiraan kunjungan wisatawan puncak kabupaten bogor [skripsi]. Bogor (ID): Fakultas Matematika dan Ilmu Pengetahuan Alam, Institut Pertanian Bogor.

Prasetia R, Hidayat EW, Shofa RN. 2018. Pengembangan Aplikasi Panduan Pengenalan Kampus Universitas Siliwangi Berbasis Augmented Reality Pada Perangkat Android. Jurnal Teknik Informatika dan Sistem Informasi. 4(3):478-87.

Puspitasari L, Ishii K. 2016. Digital divides and mobile Internet in Indonesia: Impact of smartphones. Telematics and Informatics. 33(2):472-83.

Presiden Republik Indonesia. Peraturan Pemerintah Republik Indonesia No. 19 tahun 2005 tentang standar nasional pendidikan, Pasal 42, ayat 1-2.

Statista. 2020. Number of mobile phone users in Indonesia from 2013 to 2020 (in millions) [Internet]. [diakses 2020 Mei 8]. Tersedia pada: statista.com/statistics/321485/ smartphone-user-penetration-in-indonesia/ 